\begin{tabular}{cc|c}
\hline Tar. Bil. Der. & Journal of Agricultural Sciences \\
& $\begin{array}{c}\text { Dergi web sayfası: } \\
\text { www.agri.ankara.edu.tr/dergi }\end{array}$ & Journal homepage: \\
& www.agri.ankara.edu.tr/journal
\end{tabular}

\title{
Use of Principal Coordinate Analysis for Measuring GE Interactions in Rain-Fed Durum Wheat Genotypes
}

\author{
Rahmatollah KARIMIZADEH ${ }^{\mathrm{a}, \mathrm{c}}$, Ali ASGHARI ${ }^{\mathrm{a}}$, Rahim CHINIPARDAZ ${ }^{\mathrm{b}}$, Omid SOFALIAN $^{\mathrm{d}}$, Abdolali \\ GHAFFARI $^{\mathrm{e}}$ Kamal SHAHBAZI $^{\mathrm{f}}$, Tahmasb HOSSEINPOUR ${ }^{\mathrm{g}}$, Hassan GHOJOG ${ }^{\text {h }}$, Mohammad ARMION ${ }^{1}$ \\ ${ }^{a}$ University of Mohaghegh Ardabili, Faculty of Agriculture and Natural Resources, Department of Agronomy and Plant Breeding, Ardabil, IRAN \\ ${ }^{\boldsymbol{b}}$ Shahid Chamran University of Ahvaz, Ahvaz, IRAN \\ ${ }^{c}$ Dryland Agricultural Research Institute, Agricultural Research, Education and Extension Organization (AREEO), Gachsaran, IRAN \\ ${ }^{d}$ University of Mohaghegh Ardabili, Faculty of Agriculture and Natural Resources, Department of Agronomy and Plant Breeding, Ardabil, IRAN \\ ${ }^{\boldsymbol{e}}$ West Azarbaijan Agricultural and Natural Resources Research and Education Center, Agricultural Research, Education and Extension \\ Organization (AREEO), Urmia, IRAN

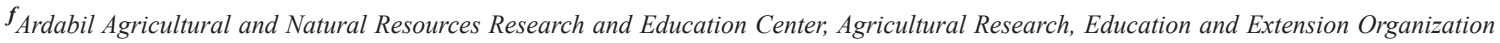 \\ (AREEO), Moghan, IRAN \\ ${ }^{g}$ Lorestan Agricultural and Natural Resources Research and Education Center, Agricultural Research, Education and Extension Organization \\ (AREEO), Khorramabad, IRAN \\ ${ }^{\boldsymbol{h}}$ Golestan Agricultural and Natural Resources Research and Education Center, Agricultural Research, Education and Extension Organization \\ (AREEO), Gonbad, IRAN \\ 'Ilam Agricultural and Natural Resources Research and Education Center, Agricultural Research, Education and Extension Organization \\ (AREEO), Ilam, IRAN
}

\section{ARTICLE INFO}

Research Article

DOI: 10.15832 ankutbd.538993

Corresponding Author: Ali ASGHARI, E-mail: ali_asgharii@yahoo.com, Tel: +98 (914) 3042117

Received: 23 October 2017, Received in Revised Form: 27 February 2018, Accepted: 01 March 2018

\begin{abstract}
Genotype $\times$ environment interactions complicate selection of superior genotypes for narrow and wide adaptation. Multienvironment yield trials of twenty durum wheat genotypes were conducted at five locations of Iran (Gachsaran, Gonbad, Moghan, Ilam and Khorram abad) over four years (2009-2013). Combined ANOVA of yield data of the twenty environments (year/location combined) revealed highly significant differences among genotypes and environments as well as significant genotype-environment interaction indicated differential performance of genotypes over test environments. The GE interaction was examined using multivariate analysis technique as principal coordinate analysis (PCOA). According to grand means and total mean yield, test environments were grouped into two main groups as high mean yield $(\mathrm{H})$ and low mean yield (L). There were eleven $H$ test environments and nine $\mathrm{L}$ test environments which analyzed in the sequential cycles. For each cycle, both scatter point diagram and minimum spanning tree plot were drawn. The identified most stable genotypes with dynamic stability concept and based on the minimum spanning tree plots and centroid distances were G12 (3342 $\left.\mathrm{kg} \mathrm{ha}^{-1}\right), \mathrm{G} 10\left(3470.3 \mathrm{~kg} \mathrm{ha}^{-1}\right), \mathrm{G} 5\left(3203.0 \mathrm{~kg} \mathrm{ha}^{-1}\right)$, and G1 $\left(3263.5 \mathrm{~kg} \mathrm{ha}^{-1}\right)$, and therefore could be recommended for unfavorable or poor conditions. Genotypes G10 (3470.3 $\left.\mathrm{kg} \mathrm{ha}^{-1}\right)$ and G9 (3404.2 $\left.\mathrm{kg} \mathrm{ha}^{-1}\right)$ were located several times in the vertex positions of high cycles according to the principal coordinates analysis (PCOA) and therefore could be recommended for favorable or rich conditions. Finally, the results of principal coordinates analysis in general confirmed the breeding value of the genotypes, obtained on the basis of the yield stability evaluation.
\end{abstract}

Keywords: Adaptation; Environment; Interaction; Genotype; Stability; Triticum turgidum 


\section{Introduction}

During the past 50 years, agricultural research and technology transfer have helped increase the output of world crops two and a half-fold. Ruttan (1998), while summarizing the world's future food situation, referred to the "2-4-6-8" scenario, which means a doubling of population, a quadrupling of agricultural production, a sextupling of energy production, and an octupling of the size of the global economy by 2050. Durum wheat (Triticum turgidum var. durum) is one of the most important cereal crops in the world and grown on only 8 to $10 \%$ of all the wheat-cultivated area (FAO 2015). Durum wheat is better adapted to semiarid environments compered to bread wheat and is a crop adapted to marginal lands (Sabaghnia et al 2013a; Karimizadeh et al 2016). Iran imports considerable amount of durum wheat due to low quantity and quality of its own produced durum wheat (Sabaghnia et al 2013b; Karimizadeh et al 2016). Durum wheat production has been increasing globally since the 1950 s and has currently reached about 33 million tons per year (Ma et al 2013). Crop performance, the observed phenotype, is a function of genotype-variety or cultivar, environment, and GE interaction. Genotypeenvironment interaction occurs when different cultivars or genotypes respond differently to diverse environments (Karimizadeh et al 2016). Expression of a phenotype is a function of the genotype, the environment, and the differential sensitivity of certain genotypes to different environments, also known as GE interaction (Leon et al 2016). The penultimate success of a plant breeding program depends on its ability to provide farmers with genotypes with guaranteed superior performance (phenotype) in terms of yield and/or quality across a range of environments. While there can be genotypes that do well across a wide range of conditions (widely adapted genotypes), there are also genotypes that perform well exclusively under a restricted set of environments or specifically adapted genotypes (Akcura et al 2009; Karimizadeh et al 2012a; Mohammadi et al 2012; Karimizadeh et al 2016).

Different yield stability statistics proposed to characterize GE interactions in multi-environment trials and several methods have been proposed to evaluate stability. These methods could be dividing by parametric, nonparametric and multivariate types. Several multivariate procedures have been proposed to explore GE interaction including principal component analysis (PCA), additive main effects and multiplicative interactions (AMMI), genotype plus GE interaction biplot (GGE) analysis and principal coordinate analysis (PCOA).

Principal Coordinates Analysis (multidimensional scaling) is a method to explore and to visualize similarities or dissimilarities of data (Westcott 1986). It starts with a similarity matrix or dissimilarity matrix (distance matrix) and assigns for each item a location in a low-dimensional space, e.g. as a 3D graphics (Gower 1966; Ibanmez et al 2001; Zuur et al 2007). PCOA is an eigen-analysis and computes a series of eigenvalues and eigenvectors that each eigenvalue has an eigenvector, and there are as several eigenvectors and eigenvalues. PCOA is a generalization of PCA and involves with measurement of similarity between variables. The main differences between PCOA and PCA are; (1) PCA explores for structure in the variables, PCOA explores for similarities between items, (2) PCA decreases variable dimensionality while PCOA analyses a distance matrix, and (3) the output of a PCOA is a set of coordinates on a number of derived axes such that similar cases are close together. It is not possible to associate these axes with any variables (Tabachnick \& Fidell 2012).

Several investigations have studied the effects of environments on grain yield of different crops in arid and semi-arid regions and reported that the large magnitude of GE interaction are observed in these environmental conditions (Finlay \& Wilkinson 1963; Becker \& Leon 1988; Ilker et al 2011; Mladenov et al 2012; Mohebodini et al 2012; Sabaghnia et al 2012; Karimizadeh et al 2012b, Karimizadeh et al 2012c; Karimizadeh et al 2013; Sabaghnia et al 2013a).

The objectives in this study were to (i) evaluate the GE interaction for grain yield of durum wheat, (ii) evaluate the relationship of test environments for selecting superior genotypes within the megaenvironment, and (iii) examine the results obtained with PCOA method. 


\section{Material and Methods}

The data used in the yield analyses were recorded from 18 genotypes with two local check cultivars (Dehdasht and Seimareh) that grown for 4 cropping seasons (2009-2013) across five locations in Iran (Table 1). The locations were preventative of climatic and edaphic conditions in rain-fed durum wheat growing areas of Iran (Table 2). Moghan (Mn) in north of Iran has a sandy loam soil, Gonbad (Gd) in the north-east of Iran has a silty clay loam soil, that these areas were characterized by semiarid conditions. Khorram abad (Kd) and Ilam (Im), in western Iran, Gachsaran $(\mathrm{Gn})$, in southern of Iran, were relatively semi-arid and has silt loam, clay loam and silty clay loam soil respectivelly. The experimental design was a randomized complete block with four replicates. Seed density for each genotype was 300 seed per $\mathrm{m}^{2}$ and planting was done experimental planters machine. Each plot size had six plant rows, $7.03 \mathrm{~m}$ length with row space of $17.5 \mathrm{~cm}$ at $80 \mathrm{~kg} \mathrm{ha}^{-1}$ of phosphorus as triple super phosphate at planting time, first half $160 \mathrm{~kg} \mathrm{ha}^{-1}$ of nitrogen as ammonium nitrate at tillering, and the other half at booting stage. No disease was shown during growth period, and weed control was made by chemical method. Clodinafop-propargyl $\left(\mathrm{C}_{17} \mathrm{H}_{13} \mathrm{C}_{1} \mathrm{FNO}_{4}\right)$ and Tribenuron methyl $\left(\mathrm{C}_{15} \mathrm{H}_{17} \mathrm{~N}_{5} \mathrm{O}_{6} \mathrm{~S}\right)$ poisons by Topic and Granstar commercial names were used in field area. After physiological maturity, plots were harvested by WINTERSTEIGER AG trial thresher machine. Geographical properties in five locations presented in Table 2.

Analyses of variance were performed for each test environment. Initial statistical analyses including normality test using the AndersonDarling normality test and homogeneity test of variances using Levene test were applied. After determination of homogeneity of residuals variance via Bartlett's homogeneity test, a combined ANOVA was performed. To partition out the year (Y), site $(\mathrm{S})$, genotype $(\mathrm{G})$ and their interactions effects, genotypes and sites were considered as fixed effects while years were considered as random effects. The PCOA was performed for stability analysis with computation of a measure of similarity between two genotypes, $\mathrm{m}$ and $\mathrm{n}$, in a given test environment as equation 1 (Westcott 1986).

$$
S_{i(m, n)}=\left[H_{i}-\left(m_{i}+n_{i}\right) / 2\right] /\left(H_{i}-L_{i}\right)
$$

Where; $\mathrm{H}_{\mathrm{i}}$ is the highest mean yield of a genotype in test environment $i$; $L_{i}$ is the lowest mean yield of a genotype in test environment $i ; m_{i}$ is the mean yield of genotype $m$ in test environment $i$ and $n_{i}$ is the mean yield of genotype $n$ in test environment i. Similarity index between two genotypes ( $\mathrm{m}$ and n) was measured as the average of $S_{i(m, n)}$ across test environments when more than one test environment was used. The analysis was based on the sequential accumulation of the test environments according to their rank order, the environments being ranked in ascending order according to their overall means. Each cycle produced a two dimensional plot based on the first two PCOA scores and the minimum spanning tree plot was drawn for identification the most stable genotypes. All of the mentioned computations were done by GENSTAT 12.1 software (VSN International 2009).

\section{Results and Discussion}

The results of Anderson-Darling normality test and the Levene variances homogeneity test verified the assumptions of ANOVA and the combined analysis of variance was performed to determine the effects of environment, genotype, and GE interaction on grain yield of durum wheat genotypes. All of the studied effects including the main effects of genotype and environments as well as the GE interaction were highly significant (Table 3). Complexity of grain yield is a result of diverse processes that occur during plant development and the larger degrees of GE interaction cause to the more dissimilar the genetic systems which are controlling the physiological processes conferring adaptation to different test environments (Sabaghnia et al 2013b). The relative contributions of GE interaction effects for grain yield in this study were similar to those found in other crop adaptation investigations in rainfed environments of semi-arid areas (Karimizadeh et al 2012a; Sabaghnia et al 2013a). 
Table 1- Pedigree and origin of the 20 durum wheat genotypes studied in multi-environmental trials

\begin{tabular}{|c|c|c|}
\hline Code & Name/Pedigree & Origin \\
\hline G1 & $\begin{array}{l}\text { ACUATICO_1/RASCON_33//ACUATICO_1/3/AJAIA_12/F3LOCAL(SEL.ETHIO.135. 85)// } \\
\text { PLATA_13CDSS96Y00570S-8Y-0M-0Y-1B-0Y-0B-0B }\end{array}$ & CIMMYT \\
\hline G2 & GAUNT_10/SNITANCDSS97Y00638S-4Y-0M-0Y-0B-0B-3Y-0BLR-1Y-0B & CIMMYT \\
\hline G3 & SOMO/CROC_4//LOTUS_1/3/KITTI/4/STOT//ALTAR 84/ALDCDSS99Y00636S-0M-0Y-34Y-0M-0Y-0B & CIMMYT \\
\hline G4 & $\begin{array}{l}\text { CMH82A.1062/3/GGOVZ394//SBA81/PLC/4/AAZ_1/CREX/5/HUI//CIT71/CII/6/STOT//ALTAR 84/ } \\
\text { ALDCDSS99Y00643S-0M-0Y-16Y-0M-0Y-0B }\end{array}$ & CIMMYT \\
\hline G5 & 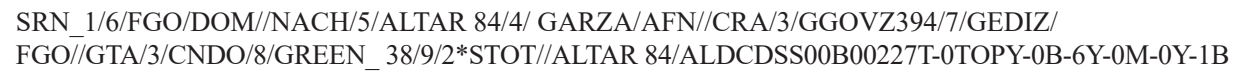 & CIMMYT \\
\hline G6 & $\begin{array}{l}\text { LLARETA INIA/YEBAS_8/3/MINIMUS_6/PLATA_16//IMMERCDSS00Y01047T-0TOPB-5Y-0BLR-1Y- } \\
\text { 0B-0Y-1B-0Y }\end{array}$ & CIMMYT \\
\hline G7 & RASCON_21/3/MQUE/ALO//FOJACDSS94Y00099S-7M-0Y-0B-1Y-0B-0BLR-5Y-0B & CIMMYT \\
\hline G8 & $\begin{array}{l}\text { GEDIZ/FGO//GTA/3/SRN_1/4/TOTUS/5/ENTE/MEXI_2//HUI/3/YAV_1/GEDIZ/6/SOMBRA_20/7/ } \\
\text { STOT//ALTAR 84/ALDCD SS97Y00835 S-0TOPM-4Y-0M-0Y-0B-0B-3Y-0BLR-1Y-0B }\end{array}$ & CIMMYT \\
\hline G9 & STOT//ALTAR 84/ALD/3/THB/CEP7780//2*MUSK_4CDSS99Y00366 S-3Y-0M-0Y-0BLR-1Y-0B-1M-0Y & CIMMYT \\
\hline G10 & $\begin{array}{l}\text { ALTAR 84/STINT//SILVER_45/3/STOT// ALTAR 84/ALDCDSS99Y 00373S-7Y-0M-0Y-0BLR-6Y-0B- } \\
\text { 1B-0Y }\end{array}$ & CIMMYT \\
\hline G11 & STOT//ALTAR 84/ALD/3/GREEN_18/FOCHA_1 //AIRON_1CDSS 99B00467S-0M-0Y-75Y-0M-0Y-2M-0Y & CIMMYT \\
\hline G12 & $\begin{array}{l}\text { RASCON_21/3/MQUE/ALO//FOJA/4/GREEN_38/BUSHEN_4/5/CADO/BOOMER_33CDSS99B01055T- } \\
\text { 0TOPY-0M-0Y-10Y-0M-0Y-1M-0Y }\end{array}$ & CIMMYT \\
\hline G13 & STOT//ALTAR 84/ALD*2/3/AUK/GUIL// GREENCDSS00Y00786T-0TOPB-9Y-0BLR-5Y-0B-0Y-1M-0Y & CIMMYT \\
\hline G14 & 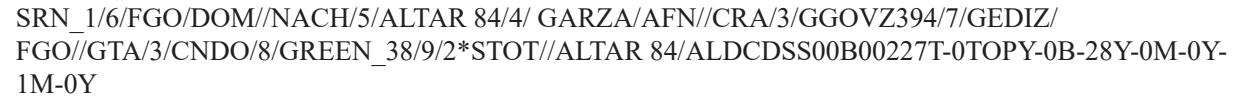 & CIMMYT \\
\hline G15 & AINZEN-1/SORD_3CDSS99B00317S-0M-0Y-104Y-0M-0Y-1M-0Y & CIMMYT \\
\hline G16 & $\begin{array}{l}\text { PLATA_8/4/GARZA/AFN//CRA/3/GTA/5/RASCON/6/CADO/BOOMER_33/7/STOT//ALTAR 84/ } \\
\text { ALDCDSS99B00843S-0TOPY-0M-0Y-5Y-0M-0Y-1B-0Y }\end{array}$ & CIMMYT \\
\hline G17 & $\begin{array}{l}\text { ALTAR 84/STINT//SILVER_45/3/CBC } 503 \text { CHILE/4/AUK/GUIL// GREENCD SS99B01115T -0TOPY- } \\
\text { 0M-0Y-1Y-0M-0Y-1B-0Y }\end{array}$ & CIMMYT \\
\hline G18 & $\begin{array}{l}\text { ALTAR 84/BINTEPE 85/3/ALTAR 84/STINT// SILVER_45/4/LHNKE/RASCON//CONA-DCD } \\
\text { SS99B01265T-0TOPY-0M-0Y-12Y-0M-0Y-1M-0Y }\end{array}$ & CIMMYT \\
\hline G19 & Saimareh & Iran \\
\hline G20 & Dehdasht & Iran \\
\hline
\end{tabular}

Table 2- Agro-climatic properties of the location tested in Iran

\begin{tabular}{|c|c|c|c|c|c|}
\hline Location & $\begin{array}{c}\text { Longitude } \\
\text { latitude }\end{array}$ & $\begin{array}{c}\text { Altitude } \\
(\mathrm{m})\end{array}$ & $\begin{array}{c}\text { Soil } \\
\text { texture }\end{array}$ & $\begin{array}{l}\text { Soil } \\
\text { type }\end{array}$ & $\begin{array}{c}\text { Rainfall } \\
(\mathrm{mm})\end{array}$ \\
\hline Gachsaran & $\begin{array}{l}50^{\circ} 50^{\prime} \mathrm{E} \\
30^{\circ} 20^{\prime} \mathrm{N}\end{array}$ & 710 & Silty Clay Loam & Regosols & 455 \\
\hline Gonbad & $\begin{array}{l}55^{\circ} 12^{\prime} \mathrm{E} \\
37^{\circ} 16^{\prime} \mathrm{N}\end{array}$ & 45 & Silty Clay Loam & Regosols & 367 \\
\hline Khorram Abad & $\begin{array}{l}48^{\circ} 12^{\prime} \mathrm{E} \\
33^{\circ} 29^{\prime} \mathrm{N}\end{array}$ & 1125 & Silt-Loam & Regosols & 433 \\
\hline Ilam & $\begin{array}{l}46^{\circ} 36^{\prime} \mathrm{E} \\
33^{\circ} 47^{\prime} \mathrm{N}\end{array}$ & 975 & Clay-Loam & Regosols & 502 \\
\hline Moghan & $\begin{array}{l}47^{\circ} 88^{\prime} \mathrm{E} \\
39^{\circ} 39^{\prime} \mathrm{N}\end{array}$ & 100 & Sandy-Loam & Cambisols & 271 \\
\hline
\end{tabular}


Table 3- Combined ANOVA of durum wheat performance trial yield data

\begin{tabular}{llll}
\hline Source & $d f$ & SS & $M S$ \\
\hline Genotype $(\mathrm{G})$ & 19 & 21661149 & $1140060^{* *}$ \\
Environment (E) & 19 & 2346434521 & $123496554^{* *}$ \\
Genotype $\times$ Environment & 361 & 123280605 & $341498^{* *}$ \\
Error & 1140 & 115619600 & 101421 \\
Total & 1599 & 2694270223 & 1684972 \\
\hline
\end{tabular}

**, significant at $1 \%$ probability level

The grain yield of durum wheat genotypes varied from $1065.3 \mathrm{~kg} \mathrm{ha}^{-1}$ in genotype G16 grown at Ilam in the third year to $6598.3 \mathrm{~kg} \mathrm{ha}^{-1}$ at Moghan in genotype G1 grown in the first year (The table is not shown). Average mean yields varied from $2994.7 \mathrm{~kg} \mathrm{ha}^{-1}$ in G13 to $3470.3 \mathrm{~kg} \mathrm{ha}^{-1}$ in G10 (Table 4). Minimum mean yields varied from $1065.3 \mathrm{~kg} \mathrm{ha}^{-1}$ in genotype G16 to $1287.8 \mathrm{~kg} \mathrm{ha}^{-1}$ in G12, while maximum mean yield varied from $4916.0 \mathrm{~kg} \mathrm{ha}^{-1}$ in genotype G20 to $6598.3 \mathrm{~kg} \mathrm{ha}^{-1}$ in genotype G1. Average yield was not correlated with minimum mean yield $(\mathrm{r}=0.3924, \mathrm{P}>0.05)$ and while significantly and positively correlated with maximum mean yield $(\mathrm{r}=0.5926, \mathrm{P}<0.01)$, and amplitude yield $(\mathrm{r}=0.5616, \mathrm{P}=0.01)$. Minimum mean yield was not correlated with maximum mean yield $(\mathrm{r}=0.3322, \mathrm{P}>0.05)$, and amplitude yield $(\mathrm{r}=0.2104, \mathrm{P}>0.05)$. Maximum mean yield was very high positively correlated amplitude yield ( $\mathrm{r}=$ $0.9920, \mathrm{P}<0.001)$. Yield amplitudes were very large, from $3738.5 \mathrm{~kg} \mathrm{ha}^{-1}$ for $\mathrm{G} 20$ to $5414.5 \mathrm{~kg} \mathrm{ha}^{-1}$ in G1 (Table 4). The correlation results for grain yield found in this study were similar to those found in other investigations in rain-fed environments of semi-arid areas (Sabaghnia et al 2013a; Sabaghnia et al 2013b).

According to grand means and total mean yield (3192.2 $\mathrm{kg} \mathrm{ha}^{-1}$ ), test environments were grouped into two main groups as High mean yield $(\mathrm{H})$ and Low mean yield (L). There were eleven $\mathrm{H}$ test environments and nine $\mathrm{L}$ test environments which analyzed in the sequential cycles. Grain yields are analyzed for the lowest test environment (cycle L1); the second cycle (L2), the third cycle (L3) the fourth cycle (L4) involves analyzing the four lowest environments, and so on. Minimum spanning tree plots for first six low cycles in Figure 1 and for other three low cycles in Figure 2 are shown. The differences in the lengths of the branches are grotesque relative to the differences between genotypes, because the minimum spanning tree is represented in two dimensions ignoring information in the next principal coordinates axis. Regarding

Table 4- Average, maximum, minimum and amplitude of grain yield in 20 durum wheat genotypes

\begin{tabular}{clllllllll}
\hline Genotype & Average & Minimum & Maximum & Amplitude & Genotype & Average & Minimum & Maximum & Amplitude \\
\hline G1 & 3263.5 & 1183.8 & 6598.3 & 5414.5 & G11 & 3207.5 & 1109.0 & 5173.8 & 4064.8 \\
G2 & 3097.6 & 1103.5 & 5312.8 & 4209.3 & G12 & 3342.7 & 1287.8 & 6430.5 & 5142.8 \\
G3 & 3073.7 & 1078.8 & 4959.8 & 3881.0 & G13 & 2994.7 & 1147.0 & 5145.3 & 3998.3 \\
G4 & 3230.8 & 1136.0 & 5803.0 & 4667.0 & G14 & 3072.7 & 1189.5 & 4962.8 & 3773.3 \\
G5 & 3203.0 & 1318.5 & 5449.5 & 4131.0 & G15 & 3252.1 & 1115.5 & 5822.3 & 4706.8 \\
G6 & 3065.6 & 1085.8 & 5987.3 & 4901.5 & G16 & 3142.7 & 1065.3 & 5125.5 & 4060.3 \\
G7 & 3153.0 & 1108.8 & 5383.8 & 4275.0 & G17 & 3199.6 & 1130.5 & 5025.0 & 3894.5 \\
G8 & 3239.2 & 1123.3 & 5239.5 & 4116.3 & G18 & 3221.6 & 1141.0 & 5963.0 & 4822.0 \\
G9 & 3404.2 & 1132.5 & 5805.3 & 4672.8 & G19 & 3089.1 & 1141.3 & 4980.3 & 3839.0 \\
G10 & 3470.3 & 1222.5 & 5857.4 & 4634.9 & G20 & 3120.0 & 1177.5 & 4916.0 & 3738.5 \\
\hline
\end{tabular}


this limitation, Flores et al (1996) suggested using a parameter as centroid distances which is benefits from all PCOA dimensions. Rather than including all nine scatter diagrams of L cycles, the stability structures of the genotypes are explained in the text and minimum spanning tree plots corresponding to all L cycles are shown.

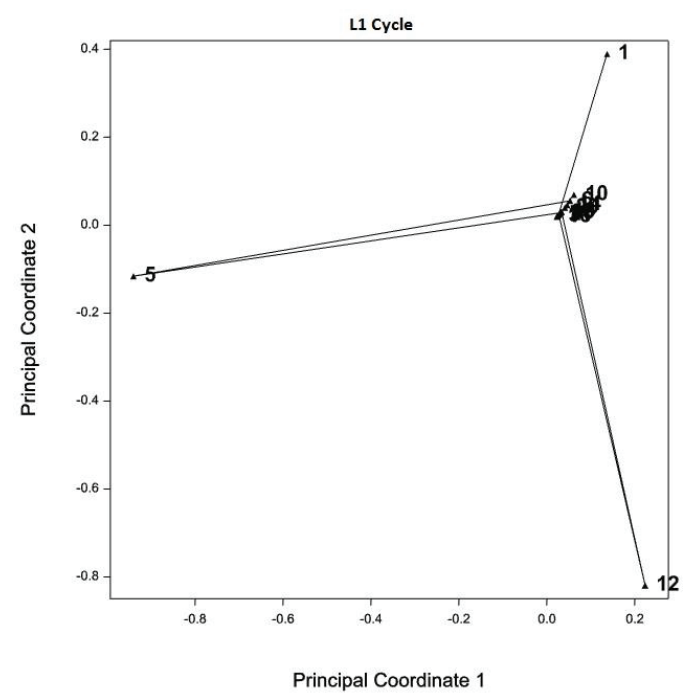

In the minimum spanning tree plots for L cycles, the high-yielding genotypes which are furthest from the center (genotypes G12, G5 and G1) were detected as the high yielding genotypes in L1 cycle while genotypes G12, G5 and G4 were detected as the high yielding genotypes in L2 cycle (Figure 1). In the minimum spanning tree plots for other $L$

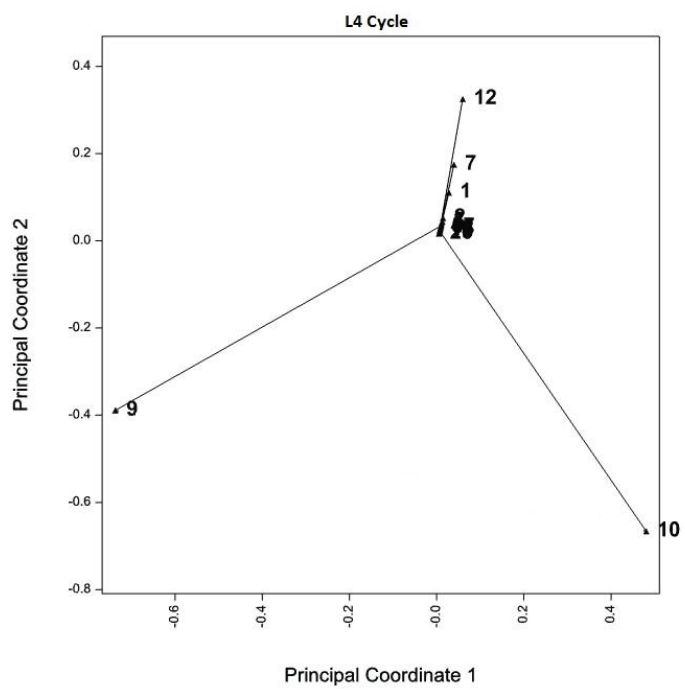

Figure 1- Example of minimum spanning tree of the first two PCOA axes for two low cycles
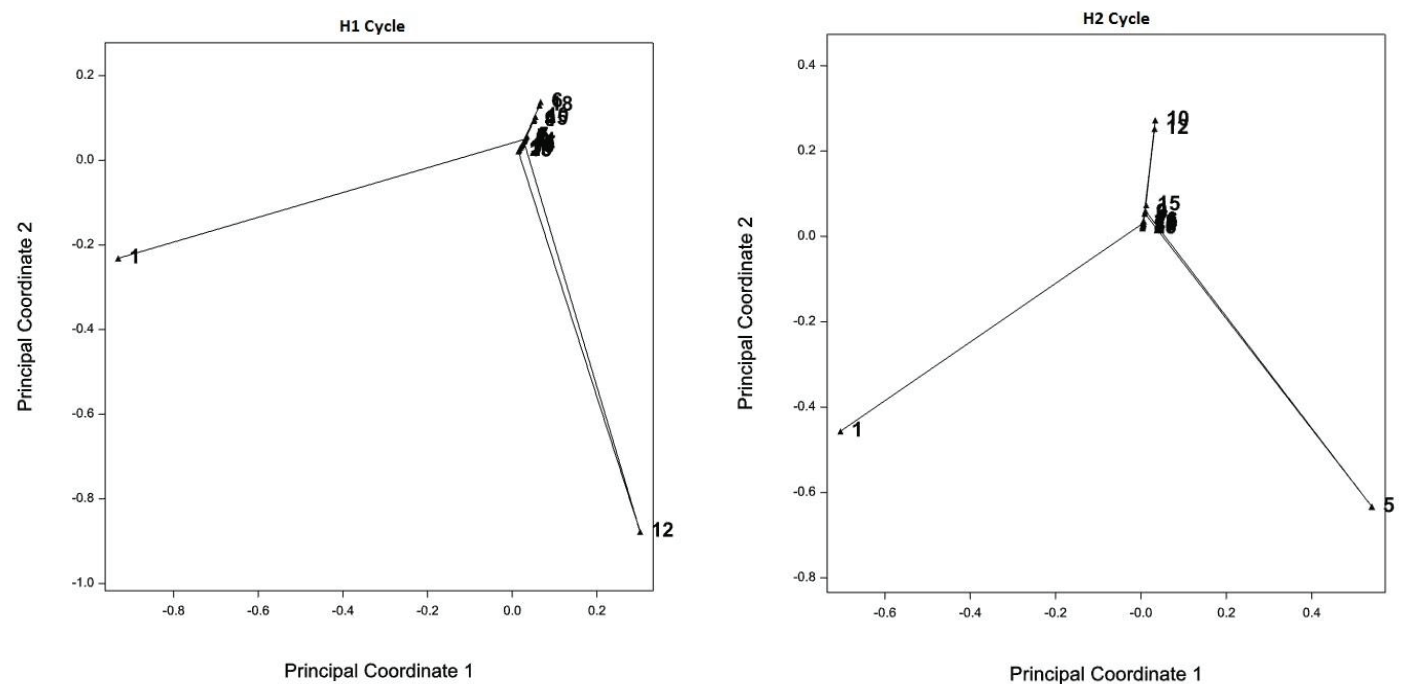

Figure 2- Example of minimum spanning tree of the first two PCOA for two high cycles 
cycles, the high-yielding genotypes are those which are furthest from the center (genotypes G5, G1 and G12) were detected as the high yielding genotypes in L3 cycle while genotypes G10, G9 and G12 were detected as the high yielding genotypes in L4 cycle (Figure 1). For using all PCOA dimensions, Flores et al (1996) and Sabaghnia et al (2013a) used first two $\mathrm{L}$ cycles plots but in this research use of nine low cycle plots. Ranking of superior genotypes based on distance from center in low cycles was given in Table 5. According tothese ranks in all $\mathrm{L}$ cycles, genotypes G12, G10, G5 and G1 could be selected for poor environmental conditions and could be identified the most favorable genotypes with high mean yield and good stability.

In the minimum spanning tree plots for $\mathrm{H}$ cycles, the high-yielding genotypes which are furthest from the center (G1, G6 and G12) were detected as the high yielding genotypes in $\mathrm{H} 1$ cycle while genotypes G1, G10 and G5 were detected as the high yielding genotypes in $\mathrm{H} 2$ cycle (Figure 2). In the minimum spanning tree plots for other $\mathrm{H}$ cycles, the high-yielding genotypes G5, G10 and G12 were detected as the high yielding genotypes in $\mathrm{H} 3$ cycle, while genotypes G10, G7 and G17 were detected as the high yielding genotypes in $\mathrm{H} 4$ cycle (Figure 2). The high-yielding genotypes G7, G10 and G8 were detected as the high yielding genotypes in $\mathrm{H} 5$ cycle, while genotypes G10, G9 and G15 were detected as the high yielding genotypes in $\mathrm{H} 6$ cycle (Figure 2). For using all PCOA dimensions, Flores et al (1996), Mohebodini et al (2012) and Sabaghnia et al (2013b) used first two H cycles plots but in this research use of eleven high cycle plots.

Ranking of superior genotypes based on distance from center in $\mathrm{H}$ cycles was given in Table 6. Based on these values, genotype G10 on the list of the best genotypes was the best genotype in rich environmental conditions. Following to this favorable genotype (G10), genotypes G9 and G12 were located in the vertex positions for four times. Accordingly, Medina et al (1999) and Sabaghnia et al (2013a) noted that the results of the PCOA agree with those obtained using the other conventional

Table 5- Ranking of superior genotypes based on distance from center in low cycles

\begin{tabular}{rccccccccccc}
\hline Genotype & Yield & L1 & L2 & L3 & L4 & L5 & L6 & L7 & L8 & L9 & $\begin{array}{c}\text { No. of top } \\
\text { position }\end{array}$ \\
\hline G1 & 3263.5 & 1 & - & 2 & - & 1 & - & 3 & - & - & 4 \\
G2 & 3097.6 & - & - & - & - & - & - & - & - & - & 0 \\
G3 & 3073.7 & - & - & - & - & - & - & - & - & - & 0 \\
G4 & 3230.8 & - & 1 & - & - & - & - & - & - & - & 1 \\
G5 & 3203.0 & 3 & 3 & 3 & - & - & 1 & - & - & - & 4 \\
G6 & 3065.6 & - & - & - & - & - & - & - & - & - & 0 \\
G7 & 3153.0 & - & - & - & - & - & - & - & - & - & 0 \\
G8 & 3239.2 & - & - & - & - & - & - & - & - & - & 0 \\
G9 & 3404.2 & - & - & - & 2 & - & - & - & - & - & 1 \\
G10 & 3470.3 & - & - & - & 3 & 2 & - & 1 & 1 & 1 & 5 \\
G11 & 3207.5 & - & - & - & - & - & 2 & - & 2 & 2 & 3 \\
G12 & 3342.7 & 2 & 2 & 1 & 1 & 3 & 3 & 2 & - & - & 7 \\
G13 & 2994.7 & - & - & - & - & - & - & - & - & - & 0 \\
G14 & 3072.7 & - & - & - & - & - & - & - & - & - & 0 \\
G15 & 3252.1 & - & - & - & - & - & - & - & - & - & 0 \\
G16 & 3142.7 & - & - & - & - & - & - & - & - & - & 0 \\
G17 & 3199.6 & - & - & - & - & - & - & - & - & - & 0 \\
G18 & 3221.6 & - & - & - & - & - & - & - & - & - & 0 \\
G19 & 3089.1 & - & - & - & - & - & - & - & - & - & 0 \\
G20 & 3120.0 & - & - & - & - & - & - & - & 3 & 3 & 2 \\
Mean & 3192.2 & & & & & & & & & \\
\hline
\end{tabular}


Table 6- Ranking of superior genotypes based on distance from center in high cycles

\begin{tabular}{cccccccccccccc}
\hline Genotype & Yield & $H 1$ & $H 2$ & $H 3$ & $H 4$ & $H 5$ & $H 6$ & $H 7$ & $H 8$ & $H 9$ & $H 10$ & H11 & $\begin{array}{c}\text { No. of top } \\
\text { position }\end{array}$ \\
\hline G1 & 3263.5 & 2 & 2 & - & - & - & - & - & - & - & - & - & 2 \\
G2 & 3097.6 & - & - & - & - & - & - & - & - & 2 & - & - & 1 \\
G3 & 3073.7 & - & - & - & - & - & - & - & - & - & - & - & 0 \\
G4 & 3230.8 & - & - & - & - & - & - & - & - & - & - & - & 0 \\
G5 & 3203.0 & - & 3 & 3 & - & - & - & - & - & - & - & - & 2 \\
G6 & 3065.6 & 1 & - & - & - & - & - & - & - & - & - & - & 1 \\
G7 & 3153.0 & - & - & - & 1 & 2 & - & - & - & - & - & - & 2 \\
G8 & 3239.2 & - & - & - & - & 3 & - & 1 & 3 & - & - & - & 3 \\
G9 & 3404.2 & - & - & - & - & - & 3 & 3 & 1 & - & 1 & - & 4 \\
G10 & 3470.3 & - & 1 & 2 & 2 & 1 & 1 & 2 & 2 & 3 & 3 & 1 & 10 \\
G11 & 3207.5 & - & - & - & - & - & - & - & - & - & - & - & 0 \\
G12 & 3342.7 & 3 & - & 1 & - & - & - & - & - & - & 2 & 2 & 4 \\
G13 & 2994.7 & - & - & - & - & - & - & - & - & - & - & - & 0 \\
G14 & 3072.7 & - & - & - & - & - & - & - & - & 1 & - & - & 1 \\
G15 & 3252.1 & - & - & - & - & - & 2 & - & - & - & - & - & 1 \\
G16 & 3142.7 & - & - & - & - & - & - & - & - & - & - & - & 0 \\
G17 & 3199.6 & - & - & - & 3 & - & - & - & - & - & - & - & 1 \\
G18 & 3221.6 & - & - & - & - & - & - & - & - & - & - & 3 & 1 \\
G19 & 3089.1 & - & - & - & - & - & - & - & - & - & - & - & 0 \\
G20 & 3120.0 & - & - & - & - & - & - & - & - & - & - & - & 0 \\
Mean & 3192.2 & & & & & & & & & & & & \\
\hline
\end{tabular}

multivariate stability analysis such as AMMI (the additive main effects and multiplicative model) model or univariate stability analysis such as joint linear regression analysis.

\section{Conclusions}

There are different methods quantifying different components of the GE interaction. The principal coordinate analysis gives a simple measure of yield stability which allows a ranking of genotypes. This model is also an effective tool in understanding complex GE interactions in multi-environment trials of durum wheat.

The principal coordinate analysis as a stability method performed in the present study quantified yield stability of genotypes. The PCOA model provided useful information for reaching definitive conclusions. According to the present study, the best genotypes available for poor dryland environmental conditions are G12 and G10, while genotypes G10 and G9 are available for rich dryland environmental conditions.

\section{Acknowledgements}

The authors thank the Iranian Dry Agricultural Research Organization for making available the plant materials, experimental locations and technical assistance.

\section{References}

Akcura M, Kaya Y \& Taner S (2009). Evaluation of durum wheat genotypes using parametric and nonparametric stability statistics. Turkish Journal of Field Crops 14(2): 111-122

Becker H C \& Leon J (1988). Stability analysis in plant breeding. Plant Breeding 101: 1-23

FAO (2015). FAOSTAT, Data stat year 2015. Food agriculture organization http://faostat.fao.org/ (verified 2 Feb. 2015), Rome, Italy

Finlay K W \& Wilkinson G N (1963). The analysis of adaptation in a plant-breeding programme. Australian Journal of Agricultural Research 14: 742-754

Flores F, Moreno M T, Martinez A \& Cubero J I (1996). Genotype $\times$ environment interaction in faba bean: 
Comparison of AMMI and principal coordinate models. Field Crops Research 47: 117-127

Gower J C (1966). Some distance properties of latent root and vector methods used in multivariate analysis. Biometrika 53: 325-338

Ibanmez M A, Direnzo M A, Samame S S, Bonamico N C \& Poverene M M (2001). Genotype-environment interaction of lovegrass forage yield in the semi-arid region of Argentina. Journal of Agricultural Science 137: $329-336$

Ilker E, Geren H, Unsal R, Sevim I, Aykut Tonk F \& Tosun M (2011). AMMI-biplot analysis of yield performances of bread wheat cultivars grown at different locations. Turkish Journal of Field Crops 16(1): 64-68

Karimizadeh R, Mohammadi M, Armion M, Shefazadeh M K \& Chalajour H (2012a). Determining heritability, reliability and stability of grain yield and yield-related components in durum wheat (Triticum durum L.). Bulgarian Journal of Agricultural Science 18(4): 595-607

Karimizadeh R, Mohammadi M, Shefazadeh M K, Mahmoodi A A, Rostami B \& Karimpour F (2012b). Relationship among and repeatability of ten stability indices for grain yield of food lentil genotypes in Iran. Turkish Journal of Field Crops 17(1): 51-61

Karimizadeh R, Mohammadi M, Sabaghnia N \& Shefazadeh M K (2012c). Using Huehn's Nonparametric Stability Statistics to Investigate Genotype $\times$ Environment Interaction. Notulae Botanicae Horti Agrobotanici Cluj-Napoca 40(1): 293-301

Karimizadeh R, Mohammadi M, Sabaghnia N, Mahmoodi A A, Roustami B, Seyyedi F \& Akbari F (2013). GGE biplot analysis of yield stability in multi-environment trials of lentil genotypes under rainfed condition. Notulae Scientia Biologicae 5(2): 256-262

Karimizadeh R, Asghari A, Chinipardaz R, Sofalian O \& Ghaffari A (2016). Determining yield stability and model selection by AMMI method in rain-fed durum wheat genotypes. Turkish Journal of Field Crops 21(2): 174-183

Leon N, Jannink J L, Edwards J W \& Kaeppler S M (2016). Introduction to a special issue on genotype by environment interaction. Crop Science 56: 2081-2089

Ma J, Zhang C Y, Yan G J \& Liu C J (2013). Improving yield and quality traits of durum wheat by introgressing chromosome segments from hexaploid wheat. Genetics and Molecular Research 12: 61206129

Medina J L, Moore P P, Shanks C H, Gil F F \& Chandler C K (1999). Genotype $\times$ environment interaction for resistance to spider mites in Fragaria. Journal of the American Society for Horticultural Science 124: 353-357

Mladenov V, Banjac B \& Milosevic M (2012). Evaluation of yield and seed requirements stability of bread wheat (Triticum aestivum L.) Via AMMI Model. Turkish Journal of Field Crops 17(2): 203-207

Mohammadi M, Karimizadeh R, Sabaghnia N \& Shefazadeh M K (2012). Genotype $\times$ Environment interaction and yield stability analysis of new improved bread wheat genotypes. Turkish Journal of Field Crops 17(1): 67-73

Mohebodini M, Karimizadeh R, Mohammadi M \& Sabaghnia N (2012). Principal coordinates analysis of genotype $\times$ environment interaction in grain yield of lentil genotypes. Agriculture and Forestry 57: 93-107

Ruttan V W (1998). Meeting the food needs of the world, In: V W Ruttan (Eds.), International agricultural research: four papers, Department of Applied Economics, University of Minnesota, Minneapolis, MN, pp. 98-104

Sabaghnia N, Karimizadeh R \& Mohammadi M (2012). Genotype by environment interaction and stability analysis for grain yield of lentil genotypes. Žemdirbysté -Agriculture 99(3): 305-312

Sabaghnia N, Mohammadi M \& Karimizadeh R (2013a). Principal coordinate analysis of genotype $\times$ environment interaction for grain yield of bread wheat in the semi-arid regions. Genetika 45(3): 691-701

Sabaghnia N, Karimizadeh R \& Mohammadi M (2013b). Principal coordinate analysis of yield stability performances of grain yield in durum wheat genotypes. Jordan Journal of Agricultural Sciences 9(4): 544-560

Tabachnick G B \& Fidell L S (2012). Using multivariate statistics. Pearson Publishers, India

VSN International (2009) GENSTAT Committee, GENSTAT 12 release 1, Reference Manual. Clarendon Press, Oxford, UK

Westcott B (1986). Some methods of analyzing genotypeenvironment interaction. Heredity 56: 243-253

Zuur A F, Leno E N \& Smith G M (2007). Statistics for biology and health-analyzing ecological data, Springer Publishers, New York 